Journal of Hard Tissue Biology 25[3] (2016) 269-276 (C) 2016 The Hard Tissue Biology Network Association Printed in Japan, All rights reserved. Original CODEN-JHTBFF, ISSN 1341-7649

\title{
Construction and Characterization of Three-Dimensional Silk Fibroin-Gelatin Scaffolds
}

\author{
Yang Du, Xiu-qiu Gao, Zhi-ying Wang, Ding Jin, Shuang Tong and Xu-kai Wang \\ Department of Oral and Maxillofacial Surgery, School of Stomatology, China Medical University, Shenyang, China \\ (Accepted for publication, April 18, 2016)
}

\begin{abstract}
The objective of the study was to discuss the construction methods, characterization and biocompatibility of silk fibroin-gelatin (SF-G) three-dimensional scaffolds which meet the requirements of bone tissue engineering scaffolds. Silk fibroin (SF) and gelatin $(\mathrm{G})$ were lyophilized at different temperature such as $-20{ }^{\circ} \mathrm{C},-40{ }^{\circ} \mathrm{C},-60{ }^{\circ} \mathrm{C},-80{ }^{\circ} \mathrm{C}$ then to make the composite scaffold materials crosslinked by genipin and methanol. Then to make composite materials, in order to find out the different temperature and crosslinking agent of SF and G, the following indexes including pore size, porosity, the water absorption and determination of mechanical properties were determined. The most appropriate condition of making SF-G scaffolds was prefreezing temperature is $-40{ }^{\circ} \mathrm{C}$ and cross-linked by genipin, which could meet the physicochemical requirements of bone tissue engineering.
\end{abstract}

Key words: Silk fibroin, Gelatin, Scaffolds, Bone tissue engineering, Osteoblast

\section{Introduction}

Bone tissue engineering is a new research area that has attracted much attention with the aim of repairing tissue defects and regenerating new tissue. Recent new approaches of bone tissue engineering are based on the use of tissue compatible scaffolds, Developing and improving tissue engineering scaffolds are pressing issues in tissue engineering and regenerative medicine today. Low-immunogenicity biomaterials that can maintain cell adhesion and proliferation, are required for a technological breakthrough in these fields. Gelatin are an example of such advanced materials. An important advantage of gelatin is the materials are characterized by a higher biocompatibility ${ }^{1,2)}$ However, the use of gelatin is limited by its mechanical properties, while articles made of silk fibroin demonstrate a good biocompatibility, along with high mechanical resistance and elasticity. The availability of silk, its water solubility, biodegradability with the formation of amino acids, the availability of easily accessible chemical groups for functional modification, the possibility of using gas sterilization, and suitability for composite materials are additional important benefits ${ }^{3)}$. The increasing number of publications and references by using fibroin for the re-generation of various organs and tissues (tendons, ligaments, cartilages, bone tissue, skin, liver, trachea, nerves, retina, tympanic membrane, and bladder) attests to the high

Correspondence to: Dr. Xu-kai Wang, Department of Oral and Maxillofacial Surgery, School of Stomatology, China Medical University, No.117, Nan Jing North Street, HePing District, Shenyang 110002, Liaoning Province, PR China;Tel:+8602422892451,E-mail: wangxukai757892@sina.com potential of the polymer as a material for biomedicine ${ }^{4)}$.

Different proportions $\mathrm{G}$ and SF has been lyophilized to obtain a porous material, thus we choose $\mathrm{G}$ and SF solutions were prepared at concentrations of $4 \% \mathrm{wt}$ and $4 \% \mathrm{wt}$ (weight ratio = 50: 50$)^{5}$. Although many scholars have done a lot of research work of making porous materials ${ }^{6.7)}$, pre-freezing temperature effect on the properties of porous materials rarely reported. So we take the material prepared in different pre-freezing temperatures, in order to discuss the effects of pre-freezing temperatures on the material in this experiment.

A variety of methods exist to crosslink gelatin so as to improve the scaffolds cytocompatibility, biostability, and reduce its rate of in vitro enzymatic degradation. There are many physical crosslinking methods including microwave energy, UV irradiation and thermal drying treatments. However, the degree of crosslinking is difficult to predict and maybe lead to denaturation of the protein. On the other hand, chemical crosslinking is commonly performed by methanol ${ }^{8)}$ and glutaraldehyde. But the presence of any unreacted crosslinking agent may cause cytotoxicity when implanted in the body ${ }^{9}$. To avoid it happened, a naturally occurring crosslinking agent can be used such as genipin. Genipin is obtained from its parent compound geniposide which is gained from the fruit of Genipa and can be used as a cross linker molecule for the attachment and immobilization of peptide chains to the surface of scaffold ${ }^{10)}$. It also can covalently crosslink with proteins that contain residues with primary amine groups and is about 500010000 times less cytotoxic than glutaraldehyde ${ }^{11)}$.

Although the application of genipin as a crosslinking agent 
for natural or artificial scaffolds seems prospective, it possibily has not been established SF-G scaffolds which were formed of porous material and cross-linked by it. Thus the goal of this study was to develop a tissue engineered scaffold which could promote bone healing. In this work, we performed, genipin and methanol crosslinked the gelatin and silk fibroin, and take the material prepared in different pre-freezing temperatures and investigate the biocompatibility. We hope the composite materia developed is more suitable for bone regeneration.

\section{Materials and Methods}

\section{Materials}

Raw silk was purchased from nancong (sichuan, PR China). Gelatin was purchased from Chemical Reagent (shanghai, PR China). Osteoblast cells HOS TE85 was purchased from biohermes (shanghai, China), $\mathrm{NaHCO}_{3}, \mathrm{CaCl}_{2}$ and methanol were bought from nanjing (China). All other chemicals and reagents were of analytical grade unless specifically mentioned.

\section{Preparation of silk fibroin/gelatin (SF-G) scaffold}

Bombyx mori silk fibers were treated twice with $0.5 \%(\mathrm{w} / \mathrm{w})$ $\mathrm{NaHCO}_{3}$ solution at $100{ }^{\circ} \mathrm{C}$ for $30 \mathrm{~min}$ and then rinsed with 70 ${ }^{\circ} \mathrm{C}$ distilled water to remove sericin for $30 \mathrm{~min}^{12)}$. Degummed silk was dissolved in a mixed solvent system of $\mathrm{CaCl}_{2} / \mathrm{CH}_{3} \mathrm{CH}_{2} \mathrm{OH} /$ $\mathrm{H}_{2} \mathrm{O}$ (mole ratio, 1: 2: 8) at $70{ }^{\circ} \mathrm{C}$ for $6 \mathrm{~h}$ and filtered to get a SF solution. After dialysis in a cellulose dialysis tubing $(\mathrm{MWCO}=50000)$ against distilled water for 3 days with water change every $12 \mathrm{~h}$. Put the SF solution at water bath of $80^{\circ} \mathrm{C}, 4$ $\%$ wt of SF was obtained by adjusting the water bath time. G solutions were prepared by the gelatin (Chemical Reagent (shanghai, PR China)) dissolved by distilled water. The final concentration of $\mathrm{G}$ used was $4 \%$ wt.

$\mathrm{G}$ and SF solutions were prepared in a mixed solvent system of TFA/DCM (weight ratio=50: 50) at concentrations of $4 \% \mathrm{wt}$ and $4 \%$ wt. Then join the $2 \%$ wt of Genipin for cross-linked. The prepared fibroin mixed solution mixed with a magnetic stirrer, and keep shaking at $37^{\circ} \mathrm{C}$ for $48 \mathrm{~h}$, then left to cool at room temperature. Poured the $\mathrm{G}$ and SF solution, into the homemade aluminum box, was lyophilized (VFD-2000, Boyikang, PRChina) at $-20{ }^{\circ} \mathrm{C},-40{ }^{\circ} \mathrm{C},-60{ }^{\circ} \mathrm{C},-80{ }^{\circ} \mathrm{C}$ to obtain regenerated SF-G scaffold. Then we prepared SF and G solution without genipin by the same method. In order to improve stability, dry SF-G scaffold without genipin was treated in methanol solution for $2 \mathrm{~h}$ to crystallize the SF content and neutralize the G content. SF-G scaffold was lyophilized to remove excess methanol.

\section{Scanning electron microscopy (SEM)}

To characterize the internal microstructures of all scaffolds by SEM. Fracture the samples by a razor blade in liquid nitrogen, cut into square pieces of $0.5 \times 0.5 \mathrm{~cm}$ and placed onto an aluminum stub pasted with a conducting carbon tape, coated with gold using a JEOL JFC-110E Ion Sputter for $60 \mathrm{~s}$ at $20 \mathrm{~mA}$, then to observe under the machine scanning electron microscope (JSM-TM3000, Japan). The SEM images and pore size were later analyzed using Image $\mathbf{J}$ software. For each type of scaffolds minimum 30 pores were examined.

\section{Porosity}

The porosity of the SF-G scaffolds was evaluated by hexane displacement ${ }^{13)}$. Firstly, the scaffolds were immersed in a volume $\left(V_{l}\right)$ of hexane. The total volume of hexane and hexaneimpregnated scaffold was recorded as $V_{2}$. Then, the volume difference $\left(V_{2}-V_{1}\right)$ is the volume of the polymer scaffold. In addition, the hexane-impregnated scaffold was then removed and the residual hexane volume was recorded as $\mathrm{V}_{3}$. So, the porosity of the SF-G scaffold was calculated as $\left(V_{I}-V_{3}\right) /\left(V_{2}-V_{3}\right) \times 100 \%$.

\section{Water absorption}

Water absorption property of the SF-G scaffolds was carried out by immersion in PBS $(\mathrm{pH} 7.4)$ at $37^{\circ} \mathrm{C}$ for $24 \mathrm{~h}$. At predetermined times, the samples were carefully blotted to remove excess water and massed. The sample number for each scaffold was five. The wet weight ( $W_{l}$, swollen weight) and dry weight ( $W_{2}$, dried at $37^{\circ} \mathrm{C}$ overnight) were measured. Then, the water absorption of the scaffold was measured using the following formula: Water absorption $=\left(W_{1}{ }^{\prime} W_{2}\right) / W_{2} \times 100 \%$.

Swelling property of the SF-G scaffolds was carried out according to the procedure as follow. Firstly, scaffolds should be immersed in PBS (pH 7.4) at $37^{\circ} \mathrm{C}$ for $24 \mathrm{~h}$. The sample number for each scaffold was five. With the wet volume $\left(S_{l}\right.$, swollen volume) and dry volume ( $S_{2}$, dried at $37{ }^{\circ} \mathrm{C}$ overnight) were measured. Then, the swelling absorption of the scaffold was measured using the following formula: Swelling index $=\left(S_{1}\right.$ "' $\left.S_{2}\right)$ / $S_{2} \times 100 \%$.

\section{Mechanical Properties}

The mechanical test of the scaffolds was carried out using an ZWICKZ2005 equipped with a $100 \mathrm{~N}$ at room temperature. The crosshead speed was set at $0.5 \mathrm{~mm} / \mathrm{min}$. Three samples were evaluated for each pre-freezing temperature. Cylinder-shaped samples measuring $10 \mathrm{~mm}$ in diameter and $10 \mathrm{~mm}$ in height were used. The compressive stress and strain were graphed and the average compressive strength, the compressive modulus, standard deviation were determined ${ }^{14)}$.

In our previous study, we found that the most appropriate condition is pre-freezing temperature is $-40{ }^{\circ} \mathrm{C}$ for bone tissue engineering. So we chose it for the next experiments.

\section{The osteoblast cells HOS TE85 culture}

The osteoblast cells HOS TE85 were cultured in DMEM/F12 
Yang Du et al.: Construction and Characterization of SF-G Scaffolds

medium supplemented with $10 \%$ fetal bovine serum, $2 \mathrm{mg} / \mathrm{ml}$ sodium bicarbonate, $200 \mathrm{mg} / \mathrm{ml}$ glutamine, and $100 \mathrm{mg} / \mathrm{ml}$ penicillin/streptomycin. cells were cultured in cultured in $25 \mathrm{~cm}^{2}$ flasks in a humidified incubator at $37{ }^{\circ} \mathrm{C}$ in a $5 \% \mathrm{CO}_{2}$ atmosphere. The cell culture medium was changed every day, and the cells were passaged every two days. The cells were grown to $80 \%$ confluence and detached with trypsin/ethylenediaminetetraacetic acid solution for seeding onto biomorphic scaffolds.

\section{Cell Morphology}

The SF-G scaffolds were sterilized with $75 \%$ alcohol under ultraviolet light overnight and then rinsed extensively three times with sterile PBS. Before cell culturing, scaffolds were pre-wetted by immersion in DMEM for $12 \mathrm{~h}$ in the $37{ }^{\circ} \mathrm{C}$ incubator.

To observe the morphology of HOS TE85 cells on biomorphic SF-G scaffolds, the cell-scaffold constructs after 1, 3 and 7 days of cultivation were taken from the culture plate and gently rinsed with PBS, and then fixed with $2.5 \%$ glutaraldehyde for $4 \mathrm{~h}$ at 4 ${ }^{\circ} \mathrm{C}$. Subsequently, they were dehydrated through a series of graded ethanol $(30 \%, 50 \%, 70 \%, 80 \%, 90 \%, 95 \%$ and $100 \%)$, airdried overnight, and sputtered with gold for SEM observation. Adherent cell morphology with respect to structural features of the SF-G scaffold, cell-cell interactions were assessed.

\section{MTT assay}

To study the cell proliferation by mitochondrial reduction of MTT. Briefly, after 1, 3, and 7 days of culture, scaffolds were washed with PBS, and then incubated with fresh culture medium containing MTT $(5 \mathrm{mg} / \mathrm{ml})$ for $4 \mathrm{~h}$ at $37^{\circ} \mathrm{C}$. And then, the medium was carefully removed and the resulting formazan crystals were extracted completely with dimethyl sulfoxide. Finally, $100 \mathrm{ml}$ of solution was transferred into a 96-well plate and the absorbance was read at $492 \mathrm{~nm}$ using a microplate spectrophotometer (BioTek Instruments, Winooski, VT). Three parallels were averaged for each group of SF-G scaffold samples. The fluorescent readings were converted to cell number using a calibration curve generated from the fluorescence of known cell numbers.

\section{ALP assay}

The intracellular ALP activity in the scaffolds was measured by using an ALP assaykit. Firstly, samples were cultured 1, 4, 7 and 10 days, then washed with PBS for 3 times. Samples and control group with cells were immersed in 500 microlitre cell lysis solution containing $0.1 \%$ Triton X-100 and $5 \mathrm{mM} \mathrm{MgCl}$ through overnight. The solution was moved to a tube and centrifuged at $13,000 \mathrm{rpm}$ for $10 \mathrm{~min}$ at $4{ }^{\circ} \mathrm{C}$ ALP activity was measured by mixing $50 \mu \mathrm{l}$ of supernatant with 50 microlitre p-nitrophenyl phosphate $(5 \mathrm{mM})$ in $150 \mathrm{mM}$ 2-amino-2-methyl-1-propanol buffer solution at room temperature for $30 \mathrm{~min}$ in dark. Then, the reaction was stopped by adding $50 \mu \mathrm{l}$ of $0.2 \mathrm{~N} \mathrm{NaOH}$ to denature
ALP .The OD was measured at $520 \mathrm{~nm}$ using an ELISA reader (Bio-Rad Model 550, USA).

\section{Statistical analysis}

All quantitative data were expressed as the means \pm SD. Statistical analyses were performed using the statistic program SPSS 21.0. Results were analyzed by one-way ANOVA with a Student's t-test. Probability values of less than 0.05 were considered statistically significant. Before results analyzed by oneway ANOVA, all quantitative data distributed obeyed normality.

\section{Results}

\section{General appearance and surface morphology of silk fibroin- gelatin scaffolds}

The appearances of the methanol cross-linked SF-G scaffolds were light yellow and non-cross-linked scaffolds were white, the genipin cross-linked scaffolds were light blue. Both surface asperities, strong enough to handle without broken. The SF-G scaffolds were out of shape by compression, it could recover after removal of external force. Non-cross-linked scaffolds dissolved rapidly in water. But cross-linked SF-G scaffolds were waterstable. They just swelled to a limited extent according to SF-G composition.

\section{Scanning electron microscopy (SEM)}

All of the SF-G scaffolds exhibited porous structures as revealed by SEM in Fig. 1. The composite of SF-G scaffolds is mixed well by a homogeneous method. Pores of SF-G scaffolds was approximately circular, oval or polygonal, feathered-like material on the inner wall. The SF-G scaffolds showed welloriented porous structures from the surface to the inside. Obviously, Fig. 1 showed that with the lower the freezing temperature, the SF-G scaffold pore size has been reduced, in the experimental of this article. When lyophilized at $-80^{\circ} \mathrm{C}$, the aperture of SF-G scaffolds minimum.

The SF-G scaffold with porous structures could facilitate uniform cell seeding and nutrient delivery, which are important for cell growth in a $3 \mathrm{D}$ porous scaffold (Fig. 1). To measure the pores in the SF-G scaffolds, we cut the scaffold transversally to expose the internal porous structures. The SF-G scaffolds showed \pm homogeneous porous structure. The inner pore size of the scaffolds was about 50 300 $\mu \mathrm{m}$.

In the present study, the aperture of SF-G scaffolds most between 100 300 $\mathrm{mm}$ when lyophilized at $-20{ }^{\circ} \mathrm{C}$ and $-40{ }^{\circ} \mathrm{C}$ (Fig. 1). This results meet the requirements of aperture of tissue engineering materials ${ }^{15)}$

\section{Porosity}

Table 1 revealed that porosity of methanol group and genipin group were $79.75 \pm 0.31 \%$ and $84.24 \pm 0.51 \%$. When pre- 
J.Hard Tissue Biology Vol. 25(3): 269 -276, 2016

Table 1. Properties of SF-Gt Scaffolds Prepared by Different Methods ( $x \pm s, n=5)$

\begin{tabular}{lcccccc}
\hline $\begin{array}{c}\text { Crosslinking } \\
\text { agent }\end{array}$ & Temperature & Pore size & Porosity & $\begin{array}{c}\text { Water } \\
\text { absorption }\end{array}$ & $\begin{array}{c}\text { Swelling } \\
\text { property }\end{array}$ & $\begin{array}{c}\text { Compressive } \\
\text { strength }\end{array}$ \\
\hline Methanol & $20{ }^{\circ} \mathrm{C}$ & $216 \pm 19$ & $79.75 \pm 0.31$ & $935.63 \pm 6.59$ & $9.15 \pm 0.05$ & $0.565 \pm 0.012$ \\
& $40^{\circ} \mathrm{C}$ & $186 \pm 16$ & $81.95 \pm 1.21$ & $955.11 \pm 5.79$ & $9.38 \pm 0.04$ & $0.592 \pm 0.007$ \\
& $60{ }^{\circ} \mathrm{C}$ & $127 \pm 18$ & $84.27 \pm 0.37$ & $963.87 \pm 1.99$ & $9.46 \pm 0.01$ & $0.610 \pm 0.007$ \\
& $80^{\circ} \mathrm{C}$ & $88 \pm 11$ & $87.28 \pm 1.18$ & $989.07 \pm 4.51$ & $9.96 \pm 0.07$ & $0.643 \pm 0.004$ \\
\hline Genipin & $20{ }^{\circ} \mathrm{C}$ & $223 \pm 18$ & $84.24 \pm 0.51$ & $1020.00 \pm 3.90$ & $16.49 \pm 0.25$ & $0.743 \pm 0.010$ \\
& $40^{\circ} \mathrm{C}$ & $192 \pm 15$ & $86.30 \pm 0.66$ & $1045.23 \pm 2.26$ & $16.98 \pm 0.18$ & $0.770 \pm 0.008$ \\
& $60^{\circ} \mathrm{C}$ & $120 \pm 29$ & $87.19 \pm 0.22$ & $1050.86 \pm 3.20$ & $17.39 \pm 0.16$ & $0.790 \pm 0.002$ \\
& $80^{\circ} \mathrm{C}$ & $86 \pm 16$ & $89.39 \pm 1.86$ & $1061.26 \pm 4.67$ & $17.6 \pm 0.22$ & $0.799 \pm 0.005$ \\
\hline
\end{tabular}

Mean $\pm \operatorname{SD}(n=5) p<0.05$
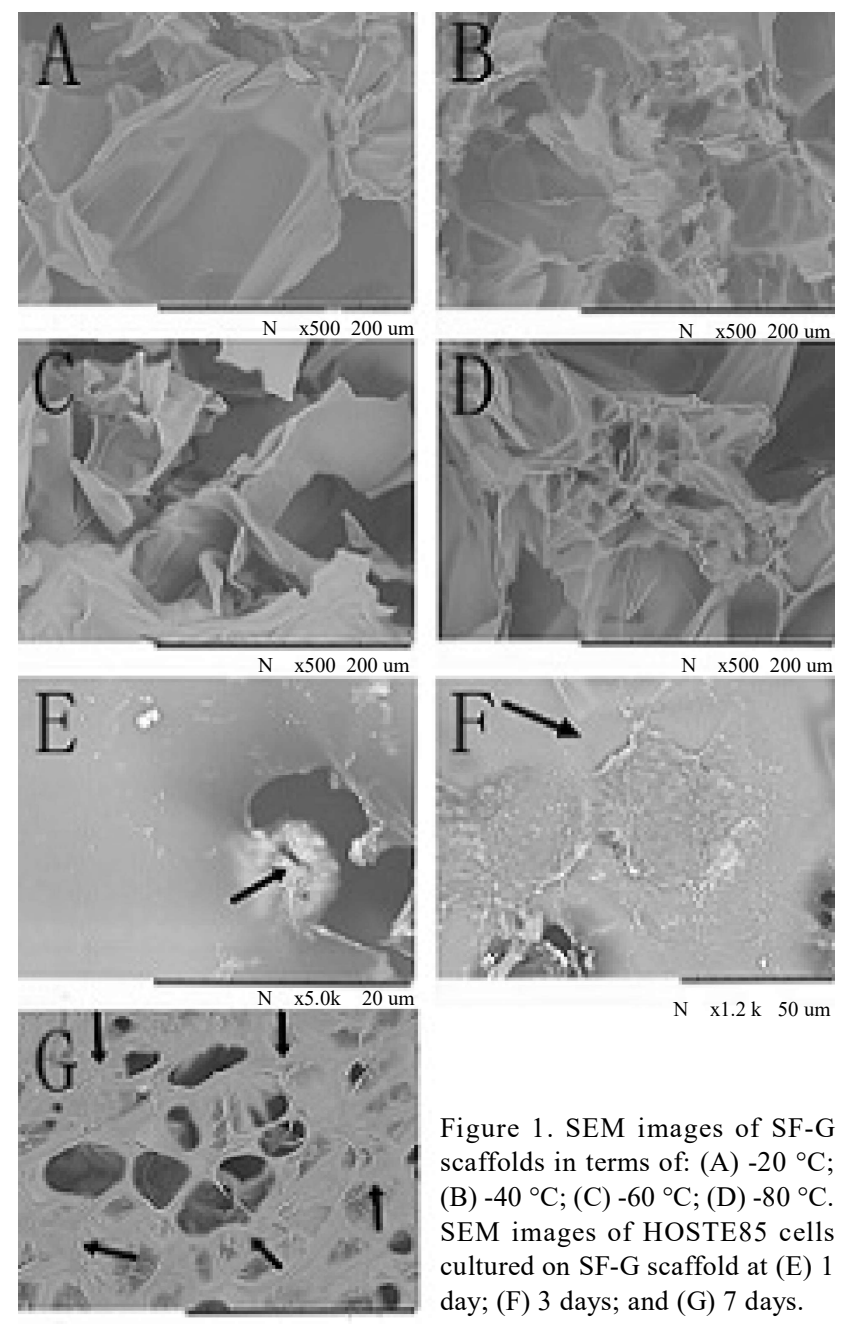

Figure 1. SEM images of SF-G scaffolds in terms of: (A) $-20^{\circ} \mathrm{C}$; (B) $-40{ }^{\circ} \mathrm{C}$; (C) $-60{ }^{\circ} \mathrm{C}$; (D) $-80{ }^{\circ} \mathrm{C}$. SEM images of HOSTE85 cells cultured on SF-G scaffold at (E) 1 day; (F) 3 days; and (G) 7 days.

freezing temperature were $-20^{\circ} \mathrm{C}$ and when, pre-freezing temperature were $-80^{\circ} \mathrm{C}$, porosity of methanol group and genipin group were $87.28 \pm 1.18 \%$ and $89.39 \pm 1.86 \%(\mathrm{P}>0.05)$. So it had no significant difference of using different crosslinking agent about the porosity of the scaffold material at the same temperature. However, pre-freezing temperatures was one of the factors influence porosity. The same result of methanol as follow, when pre-freezing temperature dropped from $-20{ }^{\circ} \mathrm{C}$ to $-80{ }^{\circ} \mathrm{C}$, porosity from $79.75 \pm 0.31 \%$ increased to $87.28 \pm 1.18 \%$; After genipin cross-linked, When pre-freezing temperature dropped from $-20^{\circ} \mathrm{C}$ to $-80^{\circ} \mathrm{C}$, porosity from $84.24 \pm 0.51 \%$ increased to $89.39 \pm$ $1.86 \%$. Therefore, when pre-freezing temperature is lowered, the porosity of the scaffolds increases.

\section{Water absorption}

The absorption ability of the SF-G scaffolds was measured in terms of degree of swelling at equilibrium. It was found that the degree of swelling of the scaffolds were in range of 9-17\%. Table1 showed that it had no significant difference of using different crosslinking agent about the absorption of the scaffold material at the same temperature. However, the absorption and swelling rate was significantly affected by the pre-freezing temperature after immersion in PBS (pH 7.4) for 24 h (Table 1).

\section{Mechanical Properties}

With increasing pre-freezing temperature, it was observed that the ultimate compressive strength increased. The $-80^{\circ} \mathrm{C}$ scaffold had a sharp increase in stress versus strain as compared to the -20 ${ }^{\circ} \mathrm{C}$ scaffold. As table 1 showed that no matter what kind of prefreezing temperature, compressive strength in genipin group was no higher than the methanol group, the compressive strength of scaffolds ( $\mathrm{p}>0.05)$.

\section{Cell morphology}

The way of cell morphology was by using a inverted microscope (Fig. 2). In primary cells, osteoblast cells HOSTE85 were a round morphology. With the number of cell increased and cells continued to grow. The third day, a large number of cells had adhered to the surface of the culture flask, the majority of the cells were get large, flattened, they became polygonal or triangular. After the six days, Cells grew well and actively proliferated, higher density was obtained in the primary and transformed cells. And the osteoblast cells were well-formed mineral nodules after 18 days. 
Yang Du et al.: Construction and Characterization of SF-G Scaffolds
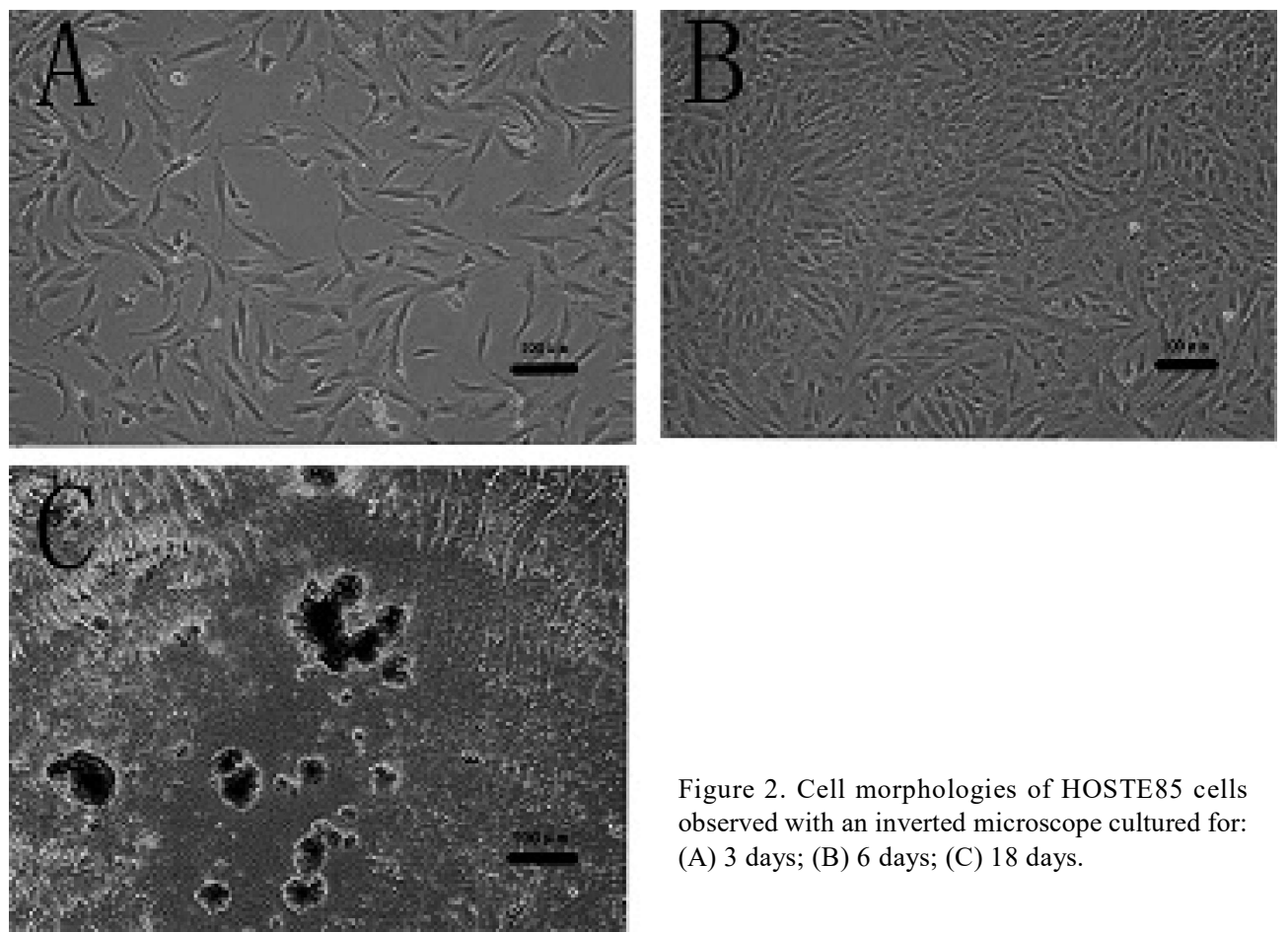

Figure 2. Cell morphologies of HOSTE85 cells observed with an inverted microscope cultured for: (A) 3 days; (B) 6 days; (C) 18 days.
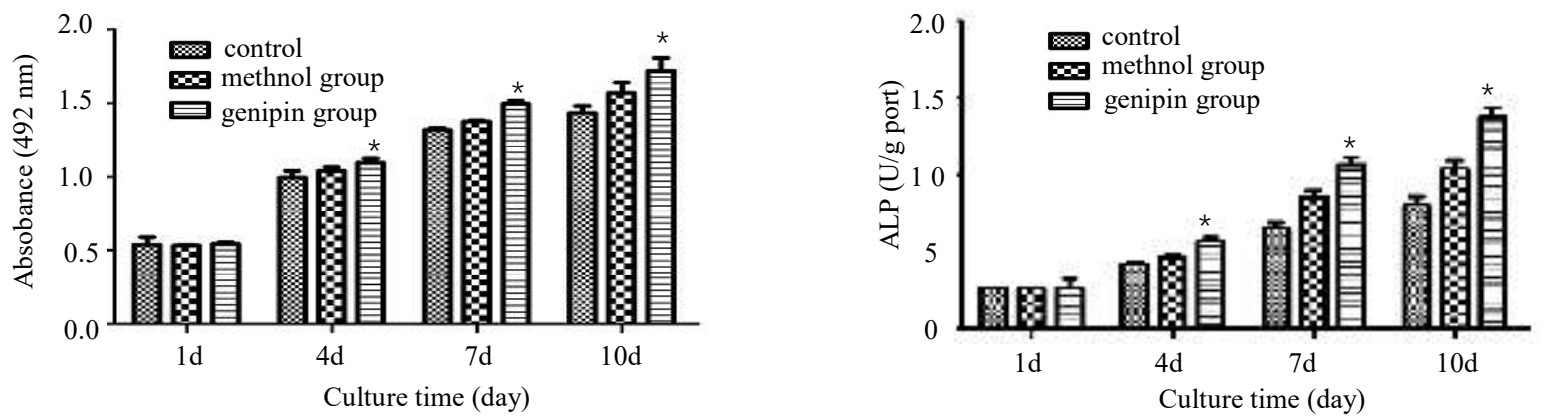

Figure 3. MTT assay for the proliferation of HOSTE85 cells cultured in genipin group scaffolds, methanol group scaffolds, and in the control group. Absorbance values for both genipin group and methanol group scaffolds gradually increased with culture time. There were no significant differences among the three groups at day 1 ( $p>0.05)$. After 3 days, data of HOSTE85 cells cultured in genipin group scaffolds were higher than those cultured in methanol group scaffolds, and the data of HOSTE85 cells cultured in both scaffolds were remarkably higher than those cultured without scaffolds with statistically significant differences $(\mathrm{p}<0.05)$. denotes $\mathrm{p}<0.05$ compared with methanol group.

\title{
SEM images of the HOS TE85 cell cultured with the SF-G scaffolds
}

SEM images of the HOS TE85 cells grown on biomorphic SF-G scaffolds for 1, 3 and 7 days. After 1 day of culture, it was found that the HOS TE85 cells exhibited a spherical morphology and uniformly located on the upper surfaces of the scaffolds and in the porous channel walls, which suggested that the HOS TE85 cells were trapped within the biomorphic SF-G scaffolds during seeding and initial attachment. As culture time increased, the cells exhibited spindle-shaped and flattened morphologies, and the

\begin{abstract}
Figure 4. ALP assay for the proliferation of HOSTE85 cells cultured in genipin group scaffolds, methanol group scaffolds, and in the control group. At day 1, there was no significant difference in OD value among the scaffolds and control group $(\mathrm{p}>0.05)$. From day 4 to day 10, data of ALP activity in genipin group scaffolds were higher than those in methanol group scaffolds, and the data of ALP in both scaffolds were remarkably was higher than those in the control group with statistically significant differences $(\mathrm{p}<0.01)$. genipin group showed the highest OD values at all culture time periods. *denotes $\mathrm{p}<0.05$ compared with the methanol group.
\end{abstract}

stretched tiny fibrils from the cells could be seen clearly. After 3 days of culture, nearly all the cells exhibited flattened morphology, and some cells started to bridge over the channels and micropores. After 7 days of culture, They exhibited typical osteoblast cell morphology and adhered tightly on the scaffolds surface or inside by formation of lamellipodia and filopodia, regarded as cells spreading, there were a number of cells present that are extending towards other cells in the culture. Cells were attached well on SF$\mathrm{G}$ scaffolds and appeared spreaded and most cells were collected together to form cellular aggregations, which is crucial for the 
viability and function of HOS TE85 cells in vitro (Fig 1).

\section{MTT assay}

The proliferation of HOS TE85 cells on genipin group scaffolds, methanol group scaffolds, and in the control group cultured for 1, 3, 5 and 7 days were compared using MTT assay. The absorbance values of both genipin group and methanol group gradually increased (Fig. 4), indicating significant cell growth within both scaffolds. Data of HOS TE85 cells cultured without scaffolds showed that cell number increased with culture time. At day 1 , HOS TE85 cells proliferated well in both genipin group and methanol group and in the control group, with no significant differences among the three groups ( $p>0.05$ ). At day 3 , data of HOS TE85 cells cultured in genipin group were higher than those cultured in methanol group, and the data of HOS TE85 cells cultured in both scaffolds were significantly higher $(\mathrm{p}<0.05)$ than those cultured without scaffolds (Fig. 3).

\section{ALP assay}

Results the ALP activities of HOS TE85 cells cultured in genipin group,methanol group, and in the control group are shown in Fig.4. At day 1, there were no significant differences in OD value among genipin group, , methanol group, and the control group ( $p>0.05$ ). From day 4 to day 10 , a significant difference in OD values was found between the scaffolds groups and the control group $(\mathrm{p}<0.01)$. At different culture time, the genipin group showed the highest OD value .thus indicating the effect of genipin group on the activity of HOS TE85 cells. As culture time increased from day 4 to 10 , the growth trend of the OD values in three groups also increased rapidly. The OD values peaked at day 10 (Fig. 4).

\section{Discussion}

Scaffold-based tissue engineering has gained great progress in the field of bone tissue engineering. Previous studies have demonstrated that the microarchitectures of porous scaffolds, porosity, pore size and interconnectivity, were crucial to translating cell-scaffold constructs into bone tissues ${ }^{16,17)}$. One of the main challenges in bone tissue engineering was to develop scaffolds with optimal mechanical properties, biocompatibility, and architecture. It is favourable for cell colonization and organization properties. Because of its inherent biological characteristics, such as biodegradability and weak antigenicity, gelatin has become optimal resource for the biomedical applications ${ }^{18)}$. However, the use of gelatin is limited by its mechanical properties. Many had found that silk fibroin demonstrate a good biocompatibility, along with high mechanical resistance and elasticity. Due to its safety, low cytotoxicity, and excellent cross-linking effectiveness, genipin has gained much attention for constructing biomedical scaffolds. Thus we hope the composite material developed is more suitable for bone regeneration.

In this study, we investigated the effect of genipin in different freeze-dried temperatures of SF-G scaffolds. Firstly, it is successful extracted the silk fibroin from natural silk. Then join the gelatin, we fabricated the scaffolds cross-linked by genipin under different freeze-dried temperatures. Genipin can spontaneously react with the amine groups on amino acids or proteins to form dark blue pigments ${ }^{19)}$. The change of color in SF-G scaffolds cross-linked with genipin indicates microstructure changes during crosslinking. The reaction between genipin and amino acids can form a monomer and further radical reaction. This reaction will cause dimerization. The mixtures of polymers formed from these reactions are the reason of blue pigment ${ }^{20)}$. In our study, light blue SF-G scaffolds were obtained in cross-linked group in different pre-freezing temperatures.

To observe the influence of cross-linking on the spatial configuration of scaffolds, further investigations were performed by SEM observation: The composite of SF-G scaffolds is mixed well by a homogeneous method. Pores of SF-G scaffolds was approximately circular, oval or polygonala and feathered-like material on the inner wall. The SF-G scaffolds showed welloriented porous structures from the surface to the inside. An interesting phenomenon could be revealed that with the lower the freezing temperature, the SF-G scaffold pore size has been reduced in the experimental in this article. Porous structures allow for interaction of the scaffold with cells ${ }^{21)}$. The pore architecture of scaffold including porosity, average pore size, and pore interconnectivity is crucial for cell survival, proliferation. It affect the formation of $3 \mathrm{D}$ bone tissue in vitro and in vivo, too. Specifically, pore size is the key when cells seed into the scaffold ${ }^{22)}$. If the scaffold pores are too small, occlusion of pore might occur, preventing cellular penetration, however, large pores prevent cell attachment. In addition, the scaffold should have an adequate porosity. It includes the magnitude of the porosity, the pore size distribution, and its interconnectivity. These also allow cell ingrowth and vascularisation and promote metabolite transport ${ }^{23)}$. The pore size larger than $100 \mathrm{im}$ and smaller than $400 \mathrm{im}$ is usually considered optimal for osteoconduction ${ }^{15}$. In our study, the SF-G scaffold had an open and interconnected pore network and a high degree of porosity $(>80 \%)$ when lyophilized at $-20^{\circ} \mathrm{C}$ and $-40^{\circ} \mathrm{C}$. The inner pore size of the SF-G scaffold was about fifty to three hundreds micron. It leads to uniform cell distribution inside the scaffolds. So, the SF-G material was an ideal scaffold to interact and integrate with the bone tissue $e^{24)}$.

We lyophilized SF-G solution at different temperature such as $-20{ }^{\circ} \mathrm{C},-40{ }^{\circ} \mathrm{C},-60{ }^{\circ} \mathrm{C},-80{ }^{\circ} \mathrm{C}$. The composite scaffold materials crosslinked by methanol and genipin. Then, experiment reveal, the porosity of the scaffold was increased with the decreasing pre-freezing temperature. The porosity and water absorption of scaffolds cross-linked by genipin were no obviously higher than 
Yang Du et al.: Construction and Characterization of SF-G Scaffolds

that of the methanol crosslinking. Scaffold porosity test results show that the more porosity ratio, the higher water absorption rate and swelling rate. The water absorption rate and swelling rate of the scaffolds were not affected by the crosslinked agent. Therefore results of its porosity and characterization are consistent with the scaffold microscopic morphology. In addition, the prefreezing temperature would significantly influence the absorption and swelling rate and the mechanical properties of scaffolds. During the pre-freezing temperature $-40{ }^{\circ} \mathrm{C}$, the measurement of mechanical properties, geometry of damage was minimum. The aperture of scaffolds were smaller, the distribution of holes more uniform at this time. With the increasing hole density, the mechanical properties of the material improved overall Meanwhile, compact structure of gelatin and high hardness ensured the integrity of scaffold.

Taking into all these factor, the pore size, porosity, the water absorption and the mechanical properties, appropriate pre-freezing temperature and crosslinking agent are vital for obtaining a stable scaffold. Therefore we suggest that the most appropriate condition is pre-freezing temperature is $-40^{\circ} \mathrm{C}$ and cross-linked by genipin for bone tissue engineering.

In order to evaluate the biological properties of biomorphic SF-G scaffolds, we culture the cells of HOS TE85 on biomorphic SF-G scaffolds in vitro. The cell morphology of HOS TE85 on SF-G scaffolds observed by SEM was similar to what is observed in standard cell culture flasks. It show completely polygonal or triangular cell morphology. These observations confirmed the cell survival and proliferation on SF-G scaffolds, assuring its biocompatibility ${ }^{25,26)}$.

Levels of cell growth and proliferation on the scaffolds control and scaffolds group were evaluated by MTT and ALP assays in vitro. The absorbance readings of the tested groups increased with culture time. At day 1 , there were no statistically significant differences $(p>0.05)$ in cell activity among the three groups. Data of HOS TE85 cells cultured in genipin group scaffolds and methanol group were higher than the cells cultured in the control group after 3 days, implying that the scaffolds were beneficial to cell development. Further, the number of osteoblasts cell on genipin group was significantly higher $(p<0.05)$ than methanol scaffolds. These results indicated that genipin group well promoted the attachment and proliferation of osteoblasts cell under the conditions of the present study. This in vitro study also suggested that genipin group could regulate bone formation through a direct effect on osteoblasts. Difference in the activity of osteoblast cells were observed in the different crosslinking agent groups. The reason for varied production of extracellular matrices in the different groups might be due to the differences in the space structure of the scaffolds ${ }^{27)}$.

Obviously, ALP assays show that the enhancement of osteoblast cells proliferation and activity by genipin group was dependent on time. The activity and proliferation of osteoblast cells was not significantly promoted at the early culture time period in Genipin group (day 1), but the effect became obvious at later culture time points (day 3-10) .Therefore, the effect of genipin group scaffolds in promoting the activity and proliferation of osteoblast cells was time dependent.

Although methanol was crosslinking agents which commonly used to SF-G scaffold, it is highly toxic on the human body and possibly remaining in scaffold. Thus, we chose genipin group for the subsequent cell and animal experiment. Reseaches of biological crosslinking agent on the experiment of SF-G has been carried out. SF-G hydrogels were cross-linked with genipin by Sun group $^{28)}$ to study the stem cells. It was found that SF-G hydrogels crosslinked with genipin can promote cell proliferation, but also induced pluripotent stem cell differentiation for epithelial ectoderm.

The goal of our study is to develop a suitable scaffold for bone tissue engineering, and the SF-G scaffold may be a good choice. We claim that with the efforts of integrating the principles of developmental biology, tissue biology, materials science and engineering, could possibly speed up the development of SF and $\mathrm{G}$ based tissue engineered product. The SF-G based bone tissue engineering research and clinical success in the near future.

The freeze-dried SF-G scaffolds were obtained in this experiment. The most appropriate condition of making SF-G scaffolds is pre-freezing temperature is $-40{ }^{\circ} \mathrm{C}$ and cross-linked by genipin, It could meet the physicochemical requirements of bone tissue engineering. In addition, the SF-G scaffolds are biocompatible and have no negative effects on the osteoblast cell HOS TE85 in vitro. Thus, the SF-G composite material is expected to be an ideal scaffold material for bone tissue engineering.

\section{Acknowledgements}

This work was supported by science and technology plan project of Liaoning province [grant number 00002012225082].

\section{Conflict of Interest}

The authors have no COI existed.

\section{References}

1. Liu X, Smith LA, Hu J and Ma PX. Biomimetic nanofibrous gelatin/apatite compositescaffolds for bone tissue engineering. Biomaterials 30: 2252-2258, 2009

2. Malafaya PB, Silva G A and Reis RL. Natural-origin polymers as carriers and scaffolds for biomolecules and cell delivery in tissue engineering applications. Adv Drug Deliv Rev 59: 207-233, 2007

3. Kundu B, Rajkhowa R, Kundu SC and Wang X. Silk fibroin biomaterials for tissue regenerations. Adv Drug Deliv Rev. 65: 457-70, 2013 
4. Kasoju N and Bora U. Silk fibroin in tissue engineering. Adv Healthc Mater 1: 393-412, 2012

5. Vorrapakdee R1, Kanokpanont S, Ratanavaraporn J, Waikakul $\mathrm{S}$, Charoenlap C and Damrongsakkul S. Modification of human cancellous bone using Thai silk fibroin and gelatin for enhanced osteoconductive potential. J Mater Sci Mater Med 24: 735-744, 2013

6. Mandal BB and Kundu SC. Cell proliferation and migration in silk fibroin 3D scaffolds. Biomaterials 30: 2956-2965, 2009

7. Wang J, Yang Q, Mao C and Zhang S. Osteogenic differentiation of bone marrow mesenchymal stem cells on the collagen/silk fibroin bi-template-induced biomimetic bone substitutes. J Biomed Mater Res Part A 100A : 29292938, 2012

8. Chomchalao P, Pongcharoen S, Sutheerawattananonda M and Tiyaboonchai W. Fibroin and fibroin blended threedimensional scaffolds for rat chondrocyte culture. Biomed Engin Online 12: 28, 2013

9. Kato K, Kikumura Y, Yamamoto M, Tomita N, Yamada S and Ikada Y. Collagen immobilization onto the surface of artificial hair for improving the tissue adhesion. Adhes Sci Techno 14: 635-650, 2000

10. Gentile P, Mattioli-Belmonte M, Chiono V, Ferretti C, Baino F, Tonda-Turo C, Vitale-Brovarone C, Pashkuleva I, Reis RL, Ciardelli G. Bioactive glass/polymer composite scaffolds mimicking bone tissue. J Biomed Mater Res A 100: 2667, 2012

11. Wua X, Liu Y, Li X, Wen P, Zhang Y, Long Y, Wang X, Guo $Y$ and Xing F. Preparation of aligned porous gelatin scaffolds by unidirectional freeze-drying method. Acta Biomater 6: 1167-1177, 2010

12. Sofia S, McCarthy MB, Gronowicz G and Kaplan DL. Functionalized silk-based biomaterials for bone formation. J Biomed Mater Res 54: 139-148, 2001

13. Kim U J, Park J, Jo Kim H, Wada M, Kaplan DL. Threedimensional aqueous-derived biomaterial scaffolds from silk fibroin. Biomaterials 26: 2775-2785, 2005

14. Tong S, Xu DP, Liu ZM and Wang XK. Construction and in vitro characterization of three-dimensional silk fibroinchitosan scaffolds. Dent Mater J 34: 475-484, 2015

15. Zhang Q, Lu H, Kawazoe N and Chen G. Pore size effect of collagen scaffolds on cartilage regeneration. Acta Biomater 10: 2005-2013, 2014

16. Sayed KE Marzahn U, John T, Hoyer M, Zreiqat H, Witthuhn A, Kohl B, Haisch A and Schulze-Tanzil G. PGAassociatedheterotopic chondrocyte cocultures: implications ofnasoseptal and auricular chondrocytes in articular cartilage repair. J Tissue Eng Regen Med 7: 61-72, 2013

17. Wang Z, Li M, Yu B, Cao L, Yang Q and Su J. Nanocalcium deficienthy droxyapatite-poly ( $\varepsilon$-caprolactone)polyethyleneglycol-pol ( $\varepsilon$-caprolactone) composite scaffolds. Int J Nanomed 7: 3123-3131, 2012

18. Lee $\mathrm{CH}$, Singla A and Lee Y. Biomedical applications of collagen. Int J Pharm 221: 1-22, 2001

19. Sung HW, Chang Y, Liang IL, Chang WH and Chen YC. Fixation of biological tissues with a naturally occurring crosslinking agent: fixation rate and effects of $\mathrm{pH}$, temperature, and initial fixative concentration. J Biomed Mater Res 52: 77-87, 2000

20. Yang D, Zhou M, Wei W, Zhu H and Fan X. Preparation of a genipin blue from egg protein and genipin. Nat Prod Res 26: 765-769, 2012

21. Lyons F, Partap S and Obrien FJ. Part 1: Scaffolds and surfaces. Technol Health Care16: 305-317, 2008

22. Mooney DJ, Baldwin DF, Suh NP, Vacanti JP and Langer R. Novel approach to fabricate porous sponges of poly (D, Llactic-co-glycolic acid) without the use of organic solvents. Biomaterials 17: 1417-1422, 1996

23. Mehdizadeh H, Bayrak ES, Lu C, Somo SI, Akar B, Brey EM and Cinar A. Agent-based modeling of porous scaffold degradation and vascularization: Optimal scaffold design based on architecture and degradation dynamics. Acta Biomater 27: 167-178, 2015

24. Yan LP, Oliveira JM, Oliveira AL, Caridade SG, Mano JF and Reis RL. Macro/microporous silk fibroin scaffolds with potential for articular cartilage and meniscus tissue engineering applications. Acta Biomaterialia 8: 289-301, 2012

25. Taddei P, Chiono V, Anghileri A, Vozzi G, Freddi G and Ciardelli G. Silk fibroin/gelatin blend films crosslinked with enzymes for biomedical applications. Macromol Biosci 13: 1492-1510, 2013

26. Wang S, Zhang Y, Wang H, Yin G and Dong Z. Fabrication and properties of the electrospun polylactide/silk fibroingelatin composite tubular scaffold. Biomacromolecules 10: 2240-2244, 2009

27. Midy V and Plouet J. Vasculotropin/vascular endothelial growth factor induces differentiation in cultured osteoblasts. Biochem Biophys Res Commun 199: 380-386, 1994

28. Sun W, Incitti T, Migliaresi C, Quattrone A, Casarosa S and Motta A. Genipin-crosslinked gelatin-silk fibroin hydrogels for modulating the behaviour of pluripotent cells. J Tissue Eng Regen Med. Jan 29, 2014 